INNOVATIONS IN PRIMARY CARE

\title{
Mentored Training Positions for Early-Career General Practitioners
}

Christopher James Weatherburn, MBCbB, MRCP, MRCGP

Shawkat Hasan, MBCbB, FRCGP, MAcadMEd

Michelle Watts, $M B C b B$, FRCGP

David Shaw, MBChB FRCGP

Ann Fam Med 2018;16:466. https://doi.org/10.1370/afm.2310.

\section{THE INNOVATION}

Novel early-career general practitioner jobs were introduced in NHS Tayside, Scotland with 2 purposes: first, to develop the skills and confidence of recently qualified general practitioners (GPs), and second, to address well-known issues of recruitment and retention in general practice.' In this innovation, the earlycareer GP has the ability to select both a supportive primary care setting where they practice as a GP and an additional specialty for which they will receive mentored training; hence candidates have the ability to work in their ideal portfolio (working in more than 1 discipline) job for the 2 years that the post lasts.

\section{WHO \& WHERE}

Practices were contacted via e-mail and asked if they would want to host an early-career GP (a fully qualified GP in the first 5 years of their career who wishes to pursue further training). Twenty-five practices provided a written summary of their practice to the early-career GP candidates. The candidates then chose from these practices. Secondary care specialties were contacted. Medical education, medicine for the elderly, musculoskeletal and physiotherapy, out-of-hours, pediatric out-of-hours, and palliative care all became involved in the program and were

Conflicts of interest: authors report none.

\section{Corresponding author}

Dr Christopher James Weatherburn, MBChB, MRCP, MRCGP

Dundee Health and Social Care Partnership Jack Martin Way, Claverhouse, DD4 9FF UK christopherweatherburn@nhs.net keen to further train GPs and have them assist with running outpatient clinics. The positions were advertised on a national recruitment website and through local networks. ${ }^{2}$ Following a competitive application process, 9 early-career GPs have been appointed, all of whom were able to select their first choice of specialty and first choice of general practice in which to work.

\section{HOW}

The posts are partly funded by the health board via Scottish Government funding designated to support GP recruitment and retention. The general practice pays a reduced session rate to the health board for each session the early-career GP works, on the basis they will support the early-career GP. This in turn provides the early-career GPs with the benefits of a salaried position.

It has been shown in the past that job satisfaction (or lack of it) is one of the main reasons GPs plan to leave the profession. ${ }^{3}$ Therefore, these positions aim to provide high job satisfaction by allowing the development of portfolio careers, and providing mentorship, a supportive team environment, and the ability to select their location of work. All of these factors that are known to provide high job satisfaction. ${ }^{4}$

\section{LEARNING}

Feedback obtained from general practice teams, early-career GPs, and specialties involved has been extremely positive, leading to a planned continuation and expansion of the program. Several new specialties are keen to be involved (including prisoner health care, substance abuse, and health care leadership) and more general practices are interested. Positive, word-of-mouth experience from early-career GPs has assisted in recruitment and indeed has become the most common recruitment mechanism. It is the belief of the authors that these positions have assisted in recruiting GPs from outside the area and retaining local GPs producing definitive portfolio GP careers.

Author affiliations, references, prior presentations, submission and acceptance dates, and acknowledgments are available at http://www.AnnFamMed.org/content/16/5/466/suppl/DC1. 